Abant Tıp Dergisi

Araştırma Makalesi / Cilt 10 Sayı 3 Yıl 2021
Abant Medical Journal

Research Article / Volume 10 Issue 3 Year 2021

\title{
Süt Çocukluğu Dönemi Kan Dolaşımı Enfeksiyon Etkenlerinin ve Antimikrobiyal Duyarlılıklarının Araştırılması
}

\author{
Investigation of Bloodstream Infections Agents and Antimicrobial Susceptibilities in Infancy \\ Period
}

\author{
Nazife AKMAN ${ }^{1}$ ID, Pınar SAĞIROĞLU ${ }^{2}$ iD, Mustafa Altay ATALAY 2 ID \\ ${ }^{1}$ Kapadokya Üniversitesi, Kapadokya Meslek Yüksek Okulu, Ürgüp, Nevşehir, Türkiye \\ ${ }^{2}$ Erciyes Üniversitesi Tıp Fakültesi Tibbi Mikrobiyoloji Anabilim Dalı, Kayseri, Türkiye
}

\section{Öz}

GíRiş ve AMAÇ: Süt çocukluğu dönemindeki kan dolaşımı enfeksiyon (KDE) etken dağılımının ve antibiyotik duyarlılıklarının belirlenmesi ampirik antibiyotik tedavisinde yol gösterici olacaktır. Bu çalışmada süt çocukluğu döneminde karşılaşılan bakteriyel KDE etkenlerinin dağılımı ve antibiyotik direncinin değerlendirilmesi amaçlanmıştır. YÖNTEM ve GEREÇLER: Ocak 2015 ile Ağustos 2020 tarihleri arasında hastaneye yatırılan bebeklerin (en az bir aylık ve 1 yaşından küçük) kan kültürü sonuçları geriye dönük olarak mikroorganizma dağılımı ve antimikrobiyal direnç açısından analiz edildi.

BULGULAR: Farklı hastalara ait 20763 kan kültürünün 17706 'sında $(\% 85,3)$ üreme saptanmamışken, $1272(\% 6,1)$ kan kültür şişesindeki üreme kontaminasyon kabul edilmiştir. Üreme tespit edilen 1785 kan kültürü sonucu çalışmamızda değerlendirmeye alınmıştır. Etkenlerin dağılımı incelendiğinde \%72'sini ( $n=1286$ ) Gram-pozitif, $\% 28$ 'sini ( $n=499$ ) Gram negatif bakteriler oluşturmaktır. En sık izole edilen Gram pozitif mikroorganizma Staphylococcus epidermidis olurken Gram negatif patojen Klebsiella pneumoniae olmuştur. Metisilin dirençli Staphylococcus aureus (MRSA) oranı \%19,7; Metisilin dirençli S. epidermidis (MRSE) oranı ise \%85,9 olarak bulunmuştur. Vankomisin dirençli Enterekok (VRE) oranı ise \%15,9 (14/88) saptanmıştır. Klebsiella spp. için Genişlemiş spektrumlu $\beta$ laktamaz (GSBL) üretim oranı \%32,3 (67/207), karbapenem direnci \%18,3 (n=33), kolistin direnci \%6,6 ( $n=12)$ saptanmıştır. Yoğun Bakım Ünitelerinden (YBÜ) alınan kan kültürlerinde diğer pediatri kliniklerine göre daha fazla oranda üreme saptanmıştır.

TARTIŞMA ve SONUÇ: Çalışmamız sonuçları Gram pozitif bakterilerde glikopeptid grubu antibiyotiklerin tedavide kullanımına devam edilebileceğini göstermektedir. Ancak Gram negatif bakteriler için elde edilen sonuçlar karbapenem türevi ilaçların tek başına kullanımını kısıtlamakta ve tedavide aminoglikozid ve polimiksin grubu antibiyotiklerin birlikte kullanımını desteklemektedir.

\section{Abstract}

INTRODUCTION: Determining the causative agent distribution and antibiotic susceptibility of bloodstream infection (BSI) in infancy will guide empirical antibiotic therapy. This study aimed to evaluate the distribution of bacterial BSI agents encountered in infancy and antibiotic resistance.

METHODS: Blood culture results of infants (at least onemonth-old and less than 1-year-old) hospitalized between January 2015 and August 2020 were retrospectively analyzed regarding microorganism distribution and antimicrobial resistance.

RESULTS: When the results of 20763 blood cultures belonging to different patients were examined; While growth was not detected in 17706 bottles (85,3\%), growth in $1272(6,1 \%)$ blood culture bottles were accepted as contamination. One thousand seven hundred eighty-five blood culture bottles were evaluated in our study. When the distribution of microorganisms is examined, $72 \%$ $(n=1286)$ are Gram-positive and 28\% (n=499) Gramnegative bacteria. The most frequently isolated Grampositive microorganism was Staphylococcus epidermidis, while the Gram-negative pathogen was Klebsiella pneumoniae. Methicillin-resistant Staphylococcus aureus (MRSA) rate was $19,7 \%$, and Methicillin-resistant S. epidermidis (MRSE) rate was $85,9 \%$. The vancomycinresistant Enterococcus (VRE) rate was 15,9\% (14/88). Extended-spectrum $\beta$-lactamase (ESBL) production rate was $32,3 \%$ (67/207), carbapenem resistance $18,3 \%(n=33)$, colistin resistance $6,6 \%(n=12)$ in Klebsiella spp. A higher growth rate was detected in blood cultures taken from Intensive Care Units (ICU) compared to other pediatric clinics.

DISCUSSION and CONCLUSION: The results of our study show that the use of glycopeptide group antibiotics can be continued in the treatment of Gram-positive bacteria. However, the results obtained for Gram-negative bacteria limit carbapenem-derived drugs alone and support their use with aminoglycoside and polymyxin group antibiotics.

Keywords: Bacteremia, infancy, bloodstream infections, antimicrobial resistance 


\section{GíRiş}

Kan dolaşımı enfeksiyonları (KDE) çocuklarda sistemik bir enflamatuvar yanıtı tetikleyebileceğinden büyük bir sorun olarak kabul edilmektedir. KDE'nin tedavisi yetersiz olduğunda, çoklu organ yetmezliği ile sepsis gelişebilir (1). Sepsis pediatrik yaş gruplarında önemli mortalite nedenlerinden biridir. Sepsis tedavisinde erken teşhis, destekleyici ve uygun antimikrobiyal tedavi çok önemlidir. Çoğunlukla antimikrobiyal tedavide tercih edilen antibiyotikler ampirik olarak seçilir. Buna karşın; metisiline dirençli Staphylococcus aureus (MRSA), vankomisin dirençli enterekok (VRE), karbapenem dirençli Enterobacterales ve çoklu antibiyotik dirençli (ÇAD) Gram negatif bakteri türlerinin dünya genelinde hızla artması uygun antibiyotik tedavisinin belirlenmesini zorlaştırmakta, KDE'nin tedavisini ve yönetimini etkilemektedir $(2,3,4)$. Çocuklarda kan dolaşımı enfeksiyonlarının uygun tedavisine rehberlik etmek için, sorumlu patojenlerin dağııım oranlarının ve bunların antimikrobiyal ajanlara duyarlııklarının bilinmesi önemlidir. Bu çalışmada, yaklaşık beş yıl süre zarfında, süt çocuklarının kan kültürlerinden izole edilen etkenlerin ve antimikrobiyal duyarlılıklarının araştırıması amaçlanmıştır.

\section{GEREÇ ve YÖNTEMLER}

Ocak 2015 - Ağustos 2020 tarihleri arasında Erciyes Üniversitesi Tıp Fakültesi Hastanelerinin pediyatri ünitelerinde tedavi görmüş 1-12 aylık pediyatrik hastalardan alınan toplam 20763 kan kültürü dahil edilmiştir. 2015 - 2016 yılları arasında BACTEC 9249 (Becton Dickinson, ABD) 2017 - 2020 yılları arasında BactAlert 3D (Biomeriux, Fransa) otomatik kan kültür sistemleri kullanılmıştır. Kan kültür şişeleri cihazlarda 5 gün boyunca inkübe edilmiştir. Sistemin pozitif sinyal verdiği şişelerden Gram boyama yapılmış ve koyun kanlı, MacConkey ve çikolata agar besiyerlerine ekim (Becton Dickinson, $A B D$ ) yapılmıştır. İnkübasyon sonrası
(37 ${ }^{\circ} \mathrm{C}^{\prime}$ de 16 -18 saat) üreme saptanan plaklarda bakteri tanımlanmasında konvansiyonel yöntemler ve Vitek 2 (Biomeriux, Fransa) veya Phoenix M50 (Becton Dickinson, ABD) otomatize sistemleri kullanılmıştır. Mikroorganizma türü ve direnç paternine bağlı olarak değişmekle birlikte antimikrobiyal duyarlılık testlerinde Avrupa Antimikrobiyal Duyarlılık Testi Komitesi (EUCAST) kriterlerine göre standart Kirby- Bauer disk difüzyon, Gradient strip test, sıvı mikrodilüsyon yöntemleriyle birlikte otomatize sistemler kullanılmıştır. Etken/kontaminasyon ayırımında Centers for Disease Control and Prevention (CDC)'nin yaygın kommensal mikroorganizmalar listesi kullanılmıştır (5). Özellikle kan kültür setinin tek şişesinde koagülaz negatif stafilokoklar (KNS)'ın ürediği durumlarda etken/ kontaminasyon ayrımı, klinikler ile iletişime geçilerek yapılmıştır.

\section{BULGULAR}

Ocak 2015 - Ağustos 2020 yılları arasında ünitemize gönderilen farklı hastalara ait 20763 kan kültürü setinin 17706 'sında $(\% 85,3)$ üreme saptanmamıştır. Kriterlerimize uyan $1785(\% 8,6)$ şişedeki üreme enfeksiyon lehine anlamlı kabul edilerek identifikasyon ve antibiyogram işlemleri yapılmıştır. Bu yaş grubundaki kontaminasyon oranı $\% 6,1(n=1272)$ olup kontaminant olarak en sık \%46,4 ( $n=590)$ oranında Staphylococcus epidermidis ve ardından \%29,6 ( $n=376)$ ile diğer KNS'ler izole edilmiştir. En çok üreme 2016 yılında $\% 21,8$ ( $n=390$ ) oranında tespit edilmiştir. Etken mikroorganizmaların en sık saptandığı klinikler sırasıyla, \%47,6 ( $n=849)$ ile yenidoğan yoğun bakım ünitesi (YBÜ) ve \%17,5 ( $n=312)$ ile pediyatrik YBÜ olmuştur (Tablo 1).

\section{KDE ile îlişkili Bakteriyel Patojenlerin Dağılımı}

Hastanemizde araştırma yaptığımız dönemde kan kültürlerinde üretilen etkenlerin $\% 72$ 'sini (1286/1785) Gram-pozitifler, \%28'sini (499/1785) Gram-negatifler oluşturmuştur. Gram pozitif bakteriler içinde ilk sırayı $\% 36,2(n=647)$ ile S.epidermidis alırken bunu \%21,2 ( $n=380)$ ile 
diğer KNS ler takip etmiştir. İzolatların \%3,6'sını (65/1785) S. aureus, \%9,5'ini (171/1785) Enterekoklar oluşturmuştur. Gram negatif bakterilerde ise en sık izole edilen mikroorganizma \%10,1 ( $\mathrm{n}=180)$ ile Klebsiella pneumoniae olmuştur. Ardından bunu sırasıyla Acinetobacter baumannii \%3,1 $\quad(n=56)$ ve Pseudomonas aeruginosa \%3 (n=54) takip etmiştir (Tablo 2).

\section{KDE ile İlişkili Bakteriyel Patojenlerin Antibiyotik Duyarlılık Analizi}

En sık izole edilen Gram pozitif mikroorganizmaların antibiyotiklere duyarlılıkları Tablo 3'te yer almaktadır.

S. aureus izolatlarının $15^{\prime}$ inde metisilin direnci saptanmış olup direnç oranı $\% 19,7$, Metisilin dirençli S.epidermidis (MRSE) oranı \%85,9 (556/647) olarak bulunmuş olup yıllara göre değişim oranı Şekil 1 de verilmiştir. S. epidermidis izolatlarının glikopeptidler dışında, test edilen tüm antibiyotiklere yüksek düzeyde direnç gösterdiği görülmüştür.

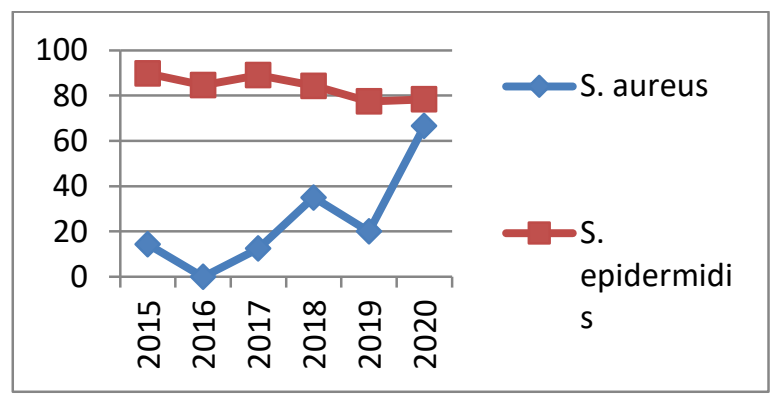

Şekil 1. S. aureus ve S. epidermidis izolatlarının yıllara göre metisilin direnç analizi

E. faecalis izolatlarının hiçbirinde vankomisinteikoplanin direnci saptanmamıştır ve izolatların ampisilin, siprofloksasin direnç oranları \%9,01 (9/88) bulunmuştur. E. faecium izolatlarında vankomisin-teikoplanin direnci \%14,4 (12/83) olup yıllara göre vankomisin-teikoplanin direnç analizi Şekil 2 de verilmiştir. Bu izolatlara en etkili antibiyotik linezolid olarak bulunmuştur ve $E$. faecium izolatlarında çoklu ilaç direnci (ÇiD) oranı $\% 74,4$ olarak saptanmıştır.

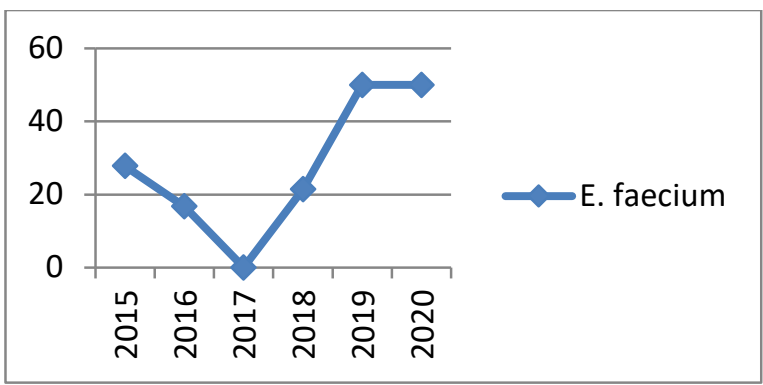

Şekil 2. E. faecium izolatlarının yıllara göre vakomisinteikoplanin direnç analizi

En sık izole edilen Gram negatif mikroorganizmaların antibiyotiklere duyarlılıkları Tablo 4'te yer almaktadır. K. pneumoniae'daki sefepim, seftazidim ve sefotaksim direnci $\% 57,7$ $(n=104)$ olarak bulunmuştur. İzolatların \%35,5'i $(n=64)$ Geniş spektrumlu beta laktamaz (GSBL) üretirken, \%18,3'ü ( $n=33$ ) karbapenem dirençli bulunmuştur. İzolatların kolistin direnç oranı $\% 6,6 \quad(n=12)$, kolistin- karbapenem direncinin birlikte sergilendiği izolat oranı ise \%6,6 ( $n=12)$ olarak tespit edilmiştir. K. pneumoniae'da ÇiD $\% 45,5$ ( $n=82$ ) olarak bulunmuştur. E. coli'deki sefepim ve sefotaksim direnci $\% 36,5 \quad(n=19)$ olarak bulundu. GSBL saptanan izolatların oranı $\% 28,8 \quad(n=52)$, karbapenem direnci tespit edilenlerin oranı ise $\% 7,6(n=4)$ olarak saptandı.

Non-fermentatif bakterilerden en sık izole edilen A. baumannii ve $P$. aureginosa mikroorganizmalarının antibiyotiklere duyarlılıkları Tablo 5'te yer almaktadır. Buna göre $P$. aureginosa'da en etkili antibiyotikler kolistin, amikasin şeklinde olup direnç oranları sırasıyla $\% 1,8 \quad(n=1)$ ve $\% 14,8 \quad(n=8)$ idi. Kökenlerin $\% 24,07$ 'inde ( $n=13$ ) çiD tespit edildi.

A. baumannii'deki meropenem direnci $\% 78,5$ $(n=44)$, siprofloksasin direnci \%83,9 ( $n=47)$, gentamisin direnci \%82,1 ( $n=56)$ ve amikasin direnci \%71,4 $(n=40)$ olarak bulundu. $\mathrm{Bu}$ izolatların \%23,2'si ( $n=13$ ) kolistin direncine de sahipti. ÇiD izolatların \%87,5'inde ( $n=49)$ saptandı. Gram negatif bakterilerin karbapenem grubundaki antibiyotiklere ve kolistine karşı gösterdikleri direncin yıllara göre değişimi Şekil 3 ve 4 'de verilmiştir. 


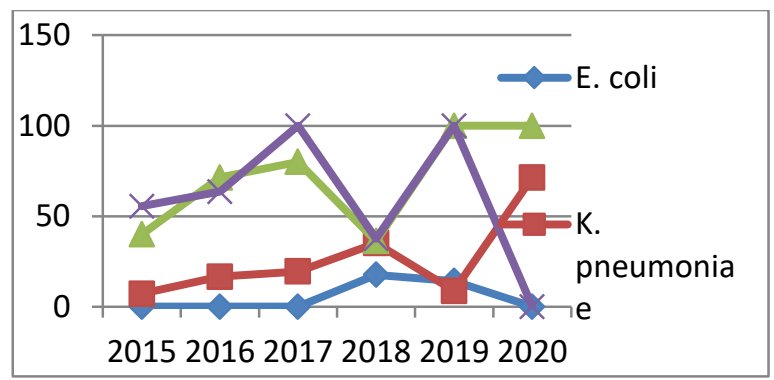

Şekil 3. K. pneumoniae, E. coli, A. baumannii ve $P$. aureginosa izolatlarının karbapenem direnç analizi

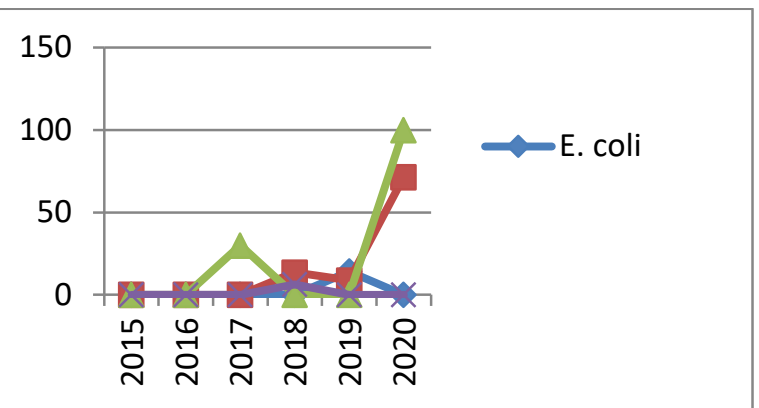

Şekil 4. K. pneumoniae, E. coli, A. baumannii ve $P$. aureginosa izolatlarının yıllara göre kolistin direnç analizi

\section{TARTIŞMA}

Pediyatrik hasta grubunda kan dolaşımı enfeksiyonları önemli morbidite ve mortalite sebebi olup hastanede kalış süresinin uzamasından ve sağlık harcamalarının artışından sorumludur (6). Bir yaş ve altındaki bebeklerde immun sistemin tam olarak gelişmemesine bağlı olarak nozokomiyal enfeksiyonlar daha fazla görülmektedir. Amerika Birleşik Devletleri'nde (ABD) 61 pediatrik YBÜ'de yapılan sürveyans çalışmasındaki 6290 nozokomiyal enfeksiyonun dağılımı incelendiğinde, vakaların \%39'nun 2 ay ile 1 yaş arasındaki süt çocuklarında görüldüğü saptanmıştır (7). Ülkemizde yapılan bir çalışmada KDE geçiren hastaların ortanca yaşı 10 ay olarak saptanmıştır (8).

Dünya genelinde yayınlanan raporlarda özellikle yenidoğan YBÜ'de (YYBÜ) meydana gelen nozokomiyal infeksiyon oranlarının gelişmekte olan ülkelerde daha yüksek olduğu gözlenmektedir (9). Bizim çalışmamızda etken mikroorganizmaların en sık saptandığı klinik
$\% 47,6$ ( $n=849)$ ile YYBÜ olmuştur.

Beş yıllık dönemde laboratuvarımıza gönderilen 20763 pediatrik kan kültür şişesinde saptanan üremelerin çalışma kriterlerimize uyumu doğrultusunda \%8,6'sı ( $n=1785$ ) anlamlı üreme, $\% 6,1 \quad(n=1272)$ ise kontaminasyon olarak kabul edilmiştir. Gündoğdu ve ark.'larının yaş grubu ayırımı yapılmaksızın nazokomiyal KDE'leri inceledikleri çalışmalarında, anlamlı üreme oranları \%13,9 iken kontaminasyon oranı \%8,4 olarak bulunmuştur (10). Dünya sağlık otoritelerince kabul edilebilir kontaminasyon oranın \%3 olduğu düşünüldüğünde çalışmamızda kontaminasyon oranları kabul edilebilir değerin üstündedir. Pediatrik hasta gruplarında kan kültürü kontaminasyon oranları erişkinlere göre daha yüksek olmakla birlikte merkezler arası farklılık göstermektedir. Ankara ilinde yapılan bir çalışmada \%7,7 bulunmuşken (11), Güneydoğu Anadolu bölgesinde yapılan çalışmada \%29,5 bulunmuştur (12). Kan kültürlerindeki kontaminasyon oranlarını etkileyen en önemli faktör kan kültürlerinin doğru ve antisepsi kurallarına uygun olarak alınmasıdır.

Çalışmamızda Gram-pozitif patojenlerin (\%72), Gram-negatiflere göre $(\% 27,4)$ daha çok enfeksiyona sebep olduğu saptanmıştır. Bu sonuç dünyadaki ve ülkemizdeki sonuçlara benzerlik göstermektedir (11-13).

Pediatrik yoğun bakım ünitelerinde, yüksek oranda invaziv cihaz kullanımı (katater vb), enfeksiyon etkeni olarak KNS'leri ön plana çıkarmaktadır (14). Çalışmamızda tespit edilen $S$. epidermidis oranı \%36,2, diğer KNS'ler ise \%21,2 şeklindeydi. Ergül ve ark. (15) yaptıkları çalışmalarında en sık görülen Gram-pozitif bakterinin KNS olduğunu $(\% 45,7)$; Stover ve ark. ise en sık tanımlanan izolatların $S$. epidermidis $(238 / 913, \% 26,1)$ ve S. aureus $(136 / 913, \% 14,9)$ olduğunu bildirmiştir (16). Doğumdan sonraki ilk hafta içinde deri ve mukozalarda kolonize olmaya başlayan KNS türlerinin, aslında bağışıklık sistemini uyarıcı ve patojen mikroorganizmalara 
karşı vücudu koruyucu etkisi bulunmaktadır. Ancak savunma mekanizmaları yetersiz olan yenidoğanlarda önemli nozokomiyal sepsis kaynağı olarak karşımıza çıkmaktadır. Hastane personeli, kontamine dezenfektanlar, yoğun bakım ekipmanları ve santral kateter, shunt gibi cansız materyaller KNS enfeksiyonu için kaynak olabilmektedir $(17,18,19)$.

Çalışmamızda, K. pneumoniae $(\% 10,1)$ en sık izole edilen Gram-negatif bakteri olmuştur. $K$. pneumoniae'yi sırasıyla A. baumannii $(\% 3,1), P$. aeruginosa $(\% 3,02)$ ve E. coli $(\% 2,9)$ takip etmiştir. İpek ve arkadaşları (20) bizim çalışmamıza benzer şekilde $K$. pneumoniae'yı $(\% 54,5)$ ve $A$. baumannii'yi $(\% 33,1)$ en sık Gramnegatif etkenler olarak rapor etmişlerdir.

Tüm dünyada olduğu gibi ülkemizde de çiD'e sahip mikroorganizmaların sayısı hızla artmaktadır. Pediatrik yaş grubunda direnç oranları erişkinlere göre daha düşük olmasına rağmen günümüzde özellikle pediatrik YBÜ ünitelerindeki çiD oranları azımsanmayacak düzeylere ulaşmıştır. Özellikle ESKAPE patojenler olarak anılan $E$. faecium, $S$. aureus, $K$. pneumoniae, A. baumannii, $P$. aeruginosa ve Enterobacter spp. türlerinin antibiyotik profillerinin ve yıllar içindeki değişimlerinin takibi dirençle mücadelede önemlidir (21). Dünya Sağlık örgütünün 2020 yılı Orta Asya ve Avrupa Antimikrobiyal Direnç Sürveyans (CAESAR) raporunda Avrupa ülkelerinde Metisilin dirençli $S$. aureus (MRSA) oranı \%25 iken ülkemizde oran \%31 olarak bildirilmiştir (22). Bizim araştırmamızda S.aureus izolatlarının 15'inde metisilin direnci saptanmış olup direnç oranı $\% 19,7$ olarak tespit edilmiştir. MRSA prevalansı son zamanlarda ABD'de ve bazı Avrupa ülkelerinde iyileştirilmiş enfeksiyon kontrol stratejileri nedeniyle azalmıştır $(23,24)$. Bununla birlikte, bazı gelişmekte olan ülkelerde, toplum kökenli MRSA daha invaziv ve bulaşıcı hale geldiği için bunu hastane ile ilişkili MRSA'dan ayırt etmek giderek zorlaşmaktadır (25). Çalışmamız sonuçlarına göre metisilin direnci $S$. epidermidis izolatlarında $\quad \% 85,9 \quad(556 / 647) \quad$ olarak bulunmuştur. Yıllar içinde metisilin direncinin özellikle $S$. aureus izolatlarında arttı̆̆ı, $S$. epidermidis izolatları için benzer kaldığı Şekil 1'de görülmektedir.

Enterokok türlerinde görülen glikopeptid direnci bir başka sorundur ve çalışmamızdaki vankomisin direnci sadece $E$. faecium izolatlarında bulunmuş ve direnç oranı \%14,4 (12/83) olarak saptanmıştır. Bu oran ülkemiz CEASAR raporu verileriyle uyumlu olarak bulunmuştur. Enterokoklardaki vankomisin direnci ülkeden ülkeye hatta aynı ülkenin şehirleri arasında bile farklılık göstermektedir. Çalışmamız verileri incelendiğinde, 2015-2017 yılları arasında vankomisin direncinin azalma eğiliminde olduğu görülmektedir. Ancak 2018 ve 2019 yılllarında ciddi bir ivme kazanarak özellikle 2019 yılında bu yaş grubunda izole edilen her E. faecium izolatının birinin vankomisin direncine sahip olduğu belirlenmiştir. Bu durumun o dönemde hastanede yaşanan olası bir salgından kaynaklandığını düşünmekteyiz. 2019 yılından bu yana ise oranın sabit kaldığı görülmüştür.

Gram negatif bakteriler arasında, çoklu ilaca dirençli Enterobacterales (özellikle Escherichia ve Klebsiella) son yirmi yılda ciddi bir sağlık tehdidi olarak ortaya çıkmıştır $(26,27)$. Enterobacterales arasında çok yüksek GSBL üretim oranlarının bir sonucu olarak karbapenem grubu antibiyotik kullanımı önemli oranda artmış ve bunun sonucunda da karbapenemlere karşı direnç ortaya çıkmıştır $(28,29)$. Avrupa Antimikrobiyal Direnç Gözetim Ağı'ndan (EARS-Net) elde edilen veriler, 2014 yılında Klebsiella pneumoniae'ya bağlı kan dolaşımı izolatlarının \%7'sinin karbapenem dirençli olduğunu ortaya koymuştur (29). Bu çalışmada GSBL üretim oranı Klebsiella spp. için \%32,3 (67/207), E. coli için \%28,8 (15/52) olarak bulunmuştur. Gram negatif enfeksiyonların tedavisinde son seçenek olarak kullanılan karbapenem ve polimiksin grubu antibiyotiklere gelişen direncin yıllar içinde çalışmamız verilerine de yansıdığı görülmektedir 
(Şekil 3 ve 4). K. pneumoniae kökenlerinde karbapenem direncinin \%18,3 ( $n=33)$, kolistin direncinin \%6,6 ( $n=12$ ) olduğu ve Acinetobacter türlerinde karbapenem direncinin $\% 78,5(n=44)$, kolistin direncinin ise $\% 23,2(n=13)$ olduğu tespit edilmiştir. VRE izolatlarında da karbapenem ve kolistin direnci için benzer durum özellikle 2020 yılında izole edilen mikrorganizmalarda karşımıza çıkmaktadır. Bu durumun özellikle 2020 yılının ikinci çeyreğinde tüm sağlık sektörüne COVID-19 pandemisinin getirdiği yükün etkisiyle hastanemizde enfeksiyon kontrol önlemlerinin yeterince uygulanamamasının bir yansıması olabileceği düşünülmektedir.

\section{Sonuç}

Bir- on iki aylık bebeklerin kan kültürü ile kanıtlanmış kan dolaşım yolu bakteriyel enfeksiyonlarının beş yıllık bir perspektifte incelendiği çalışmamız sonuçları doğrultusunda, izole edilen bakterilerin dağılımında anlamlı farklılık olmamasına karşın, özellikle yıllar içinde artan direnç oranlarının endişe verici boyutlara ulaştığı görülmektedir. Bu yaş grubunun kan kültürlerinde en çok izole edilen tür $S$. epidermidis olmuştur. İzole edilen kökenlerin çok büyük kısmının metisilin direncine sahip olmasının glikopeptid grubu antibiyotiklerin tedavide kullanımına devam edileceğini göstermektedir. Ancak çalışmamı sonucunda elde edilen veriler, Gram negatif bakterilerde artan çoklu antibiyotiklere direnç oranlarının son seçenek olarak kullanılan karbapenem türevi ilaçların tek başına kullanımını kısıtlamakta ve yan etkileri daha fazla olan aminoglikozid ve polimiksin grubu antibiyotiklerle birlikte kullanımını desteklemektedir. Sonuç olarak kan dolaşım yolu enfeksiyonlarının tanısında altın standart kabul edilen kan kültür sonuçlarının yıllar içindeki değişimlerin merkezlerce düzenli olarak takip edilmesinin hem bu enfeksiyonların tedavisine hem de dirençli bakterilerin kontrolüne katkı sağlayacağı düşüncesindeyiz.
Bilgilendirilmiş Onam: Katılımcılardan yazıı onam alınmıştır.

Çıkar Çatışması: Yazarlar çıkar çatışması beyan etmemişlerdir.

Finansal Destek: Yazarlar finansal destek beyan etmemişlerdir.

\section{KAYNAKLAR}

1. Plunkett A, Tong j. Sepsis in children. BMJ 2015;350:h3017.

2. Okeke IN, Laxminarayan R, Bhutta ZA, Duse AG, Jenkins $P$, O'Brien TF, et al, Antimicrobial Resistance in Developing Countries, Part I: Recent Trends And Current Status. Lancet Infect Dis 2005; 5:481-93.

3. Aiken AM, Allegranzi B, Scott JA, Mehtar S, Pittet D, Grundmann H. Antibiotic Resistance Needs Global Solutions, Lancet Infect Dis 2014;14(7):550-51.

4. Basmaci R, Bielicki J, Daniels R, Kissoon N, Ellis S, Balasegaram $M$, et al. Management Of Children With Multidrug-Resistant Sepsis in Low-Income And MiddleIncome Countries. The Lancet Child \& Adolescent Health 2018;2(1):8-10.

5. National Healthcare Safety Network, NHSN Organism List (All Organisms, Top Organisms, Common Commensals, $\mathrm{MBI}$ Organisms, and UTI Bacteria). Atlanta, 2018, [https://www,cdc,gov/nhsn/xls/2018NHSN-Organisms-List-Validation, $\mathrm{xlsx}$ ] (Accessed: 06.05.2021).

6. Pereira CAP, Marra AR, Camargo LFA, Pignatari ACC, Sukiennik T, Behar PRP, et al. Nosocomial Bloodstream Infections in Brazilian Pediatric Patients: Microbiology, Epidemiology, and Clinical Features. PLoS One 2013; 8(7): e68144.

7. Richards MJ, Edwards JR, Culver DH, Gaynes RP. Nosocomial infections in pediatric intensive care units in the United States, National Nosocomial Infections Surveillance System, Pediatrics, 1999 Apr;103(4): e39.

8. Akgül F. Çocuk Yoğun Bakım Ünitesinde Nozokomiyal Sepsis Epidemiyolojisi. (Uzmanlık Tezi), İzmir, Dokuz Eylül Üniversitesi, 2013. [http://acikerisim,deu,edu,tr:8080/xmlui/bitstream/h andle/20,500,12397/12889/342073, pdf?sequence=1 \&isAllowed=y] (Accessed: 06.05.2021].

9. Hsu JF, Chu SM, Lee CW, Yang PH, Lien R, Chiang MC, et al. Incidence, Clinical Characteristics and Attributable Mortality of Persistent Bloodstream Infection in The Neonatal Intensive Care Unit. PLoS One 2015;10(4): e0124567.

10. Gündoğdu A, Kılıç $H$, Kılıç Ulu A, Aydın G, Alp E. Pediyatrik Hastalarda Nozokomiyal Kan Dolaşımı Infeksiyonlarının Epidemiyolojik Özelliklerinin İncelenmesi. Klimik Derg 2016; 29:29-35.

11. Gülmez D, Gür D. Hacettepe Universitesi Ihsan 
Doğramacı Çocuk Hastanesi'nde 2000-2011 Yılları Arasında Kan Kültürlerinden İzole Edilen Mikroorganizmalar: 12 Yıllık Değerlendirme. Çocuk Enfeksiyon Dergisi 2012;6(3):79-83.

12. Yis R. Evaluation Of Blood Cultures in a Children's Hospital Located in Southeastern Anatolia. Turk Arch Pediatr 2015; 50:102-7.

13. Dawson S. Blood Culture Contamination Rate. J Hosp Infect 2015;91(2):109-10.

14. Urzedo JE, Levenhagen MM, Pedroso RS, Abdallah VO, Sabino SS, Brito DV. Nosocomial Infections in a Neonatal Intensive Care Unit During 16 Years: 19972012. Rev Soc Bras Med Trop 2014;47(3):321-6.

15. Ergül $A B$, Işık $H$, Ay Altıntop $Y$, Altuner Torun $Y$. Bir Çocuk Yoğun Bakım Biriminde Kan Kültürlerinin Geriye Dönük Değerlendirilmesi: Üç Yıllık Sonuçlar. Turk Pediatri Ars 2017; 52: 154-61.

16. Stover KR, Morrison A, Collier T, Schneider E, Wagner $\mathrm{JL}$, Capino, A. C, et al. Epidemiology and risk factors for bacteremia in pediatric and adolescent patients. Journal of pharmacy practice, 2021;34(3):360-364.

17. Von Eiff C, Peters G, Heilmann C. Pathogenesis of infections due to coagulase-negative staphylococci. Lancet Infect Dis 2002; 2: 677-85.

18. Jean-Baptiste N, Benjamin DK, Cohen-Wolkowiez $\mathrm{M}$ et al. Coagulase-negative staphylococcal infections in the neonatal intensive care unit. Infect Control Hosp Epidemiol 2011; 32: 679-86.

19. Dong Y, Speer CP. The role of Staphylococcus epidermidis in neonatal sepsis: guarding angel or pathogenic devil? Int J Med Microbiol 2014; 304: 51320.

20. İpek MŞ, Özbek E. Bloodstream Infections in a Neonatal Intensive Care Unit. Journal of Clinical and Analytical Medicine 2016;7(5):625-9.

21. Rice LB. Federal Funding for The Study of Antimicrobial Resistance in Nosocomial Pathogens: No ESKAPE. J Infect Dis, 2008;197(8):1079-81.

22. Central Asian and European Surveillance of Antimicrobial Resistance, Annual Report 2020. [https://www,euro,who,int/_data/assets/pdf_file/00 03/469200/Central-Asian-and-European-Surveillanceof-Antimicrobial-Resistance,-Annual-report-2020eng,pdf], (Accessed: 06.05.2021).

23. Purrello SM, Garau J, Giamarellos E, Mazzei T, Pea F, Soriano A, et al. Methicillin-resistant Staphylococcus aureus infections: a review of the currently available treatment options. J Glob Antimicrob Resist 2016; 7:178-86.

24. Kallen AJ, Mu Y, Bulens S, Reingold A, Petit S, Gershman $\mathrm{K}$, et al. Health care-associated invasive MRSA infections, 2005-2008. JAMA 2010; 304:641-8.

25. Sunagar R, Hegde NR, Archana GJ, Sinha AY, Nagamani $\mathrm{K}$, Isloor $\mathrm{S}$. Prevalence and genotype distribution of methicillin-resistant Staphylococcus aureus (MRSA) in
India. J Glob Antimicrob Resist 2016; 7:46-52.

26. Pitout JD, Laupland KB. Extended-spectrum betalactamase-producing Enterobacter- iaceae: an emerging public-health concern. Lancet Infect Dis 2008; 8:159-66.

27. Padmini N, Ajilda AAK, Sivakumar N, Selvakumar G. Extended spectrum b-lactamase producing Escherichia coli and Klebsiella pneumoniae: critical tools for antibiotic resistance pattern. J Basic Microbiol 2017; 57:460-70.

28. Hawkey PM. Multidrug-resistant Gram-negative bacteria: a product of globaliza-tion. J Hosp Infect 2015; 89:241-7.

29. Friedman ND, Carmeli Y, Walton AL, Schwaber MJ. Carbapenem-resistant Enter- obacteriaceae: a strategic roadmap for infection control. Infect Control Hosp Epidemiol 2017; 38:580-94. 
Akman N. ve Ark.

Tablo 1. Etken Mikroorganizmaların Yıllara Göre Kliniklerdeki Dağılımı

\begin{tabular}{|c|c|c|c|c|c|c|c|}
\hline \multirow{3}{*}{ Klinik } & \multirow{3}{*}{$\begin{array}{l}2015 \\
n(\%)\end{array}$} & \multirow{3}{*}{$\begin{array}{l}2016 \\
\text { n (\%) }\end{array}$} & \multirow{3}{*}{$\begin{array}{l}2017 \\
\text { n (\%) }\end{array}$} & \multirow{3}{*}{$\begin{array}{l}2018 \\
\text { n (\%) }\end{array}$} & \multirow{3}{*}{$\begin{array}{l}2019 \\
\text { n (\%) }\end{array}$} & \multirow{3}{*}{$\begin{array}{l}2020^{*} \\
\text { n (\%) }\end{array}$} & \multirow{3}{*}{$\begin{array}{l}\text { Toplam } \\
\text { n (\%) }\end{array}$} \\
\hline & & & & & & & \\
\hline & & & & & & & \\
\hline $\begin{array}{l}\text { Pediatrik Hematoloji- } \\
\text { Onkoloji }\end{array}$ & $9(\% 2.5)$ & $2(\% 0.5)$ & $3(\% 0.85)$ & $33(\% 7.9)$ & $5(\% 2.6)$ & & $52(\% 2.9)$ \\
\hline $\begin{array}{l}\text { Pediyatrik İnfeksiyon } \\
\text { Hastalıkları }\end{array}$ & $14(\% 3.9)$ & $19(\% 4.8)$ & $10(\% 2.8)$ & $11(\% 2.6)$ & $1(\% 0.5)$ & $2(\% 2.4)$ & $57(\% 3.2)$ \\
\hline $\begin{array}{l}\text { Pediyatrik Kemik İliği } \\
\text { Ünitesi }\end{array}$ & $2(\% 0.5)$ & $13(\% 3.3)$ & $8(\% 2.3)$ & $64(\% 15.3)$ & $24(\% 12.5)$ & $14(\% 16.8)$ & $125(\% 7.0)$ \\
\hline $\begin{array}{l}\text { Pediyatrik Nefroloji- } \\
\text { Romatoloji }\end{array}$ & $6(\% 1.7)$ & $33(\% 8.4)$ & $16(\% 4.5)$ & $5(\% 1.1)$ & & & $60(\% 3.4)$ \\
\hline Pediyatrik Nöroloji & $9(\% 2.5)$ & $9(\% 2.3)$ & $3(\% 0.85)$ & $19(\% 4.5)$ & $1(\% 0.5)$ & & $41(\% 2.3)$ \\
\hline Sütçocuğu Servisi & 39 (\%11.0) & $33(\% 8.4)$ & 37 (\%10.5) & 79 (\%18.9) & $16(\% 8.3)$ & $5(\% 6.0)$ & $209(\% 11.7)$ \\
\hline Pediyatrik YBÜ & 43 (\%12.2) & 87 (\%22.3) & $82(\% 23.3)$ & 50 (\%11.9) & $46(\% 24.0)$ & $4(\% 4.8)$ & $312(\% 17.5)$ \\
\hline Yenidoğan YBÜ & $222(\% 63.0)$ & $176(\% 45.1)$ & $178(\% 50.6)$ & $131(\% 31.4)$ & $88(\% 46.0)$ & $54(\% 65.0)$ & $849(\% 47.6)$ \\
\hline Diğer & $8(\% 2.2)$ & $18(\% 4.6)$ & $15(\% 4.3)$ & $25(\% 5.9)$ & $10(\% 5.2)$ & $4(\% 4.8)$ & $80(\% 4.5)$ \\
\hline Toplam & 352 (\%19.7) & 390 (\%21.8) & 352 (\%19.7) & 417 (\%23.4) & 191 (\%10.7) & $83(\% 4.6)$ & 1785 \\
\hline
\end{tabular}

Diğer: Dış Merkez (2), Beyin Cerrahi Poliklinik (5), Çocuk Acil (60), Çocuk Cerrahi Servis (2), Çocuk Cerrahi Poliklinik (4), Çoçuk Poliklinik (2), Enfeksiyon Hastalıkları (1), Kalp Damar Cerrahi Poliklinik (1), Kulak Burun Boğaz Klinik (1), Pediatrik Adölesan (1), Pediatrik İmmünoloji (1); YBÜ: Yoğun Bakım Ünitesi

*ilk 8 ay 
Tablo 2. Bakterilerin Dağıımı (n, \%)

\begin{tabular}{|c|c|c|}
\hline Bakteriler & Tür & n (\%) \\
\hline \multirow{10}{*}{$\begin{array}{l}\text { Gram pozitifler } \\
n=1286(\% 72.0)\end{array}$} & S. epidermidis & $647(\% 36.2)$ \\
\hline & Diğer KNS & $380(\% 21.2)$ \\
\hline & E. faecalis & $88(\% 4.9)$ \\
\hline & E. faecium & $83(\% 4.6)$ \\
\hline & S. aureus & $65(\% 3.6)$ \\
\hline & Viridans Streptokoklar & $17(\% 0.9)$ \\
\hline & Streptococcus pneumoniae & $3(\% 0.16)$ \\
\hline & Streptococcus agalactiae & $1(\% 0.05)$ \\
\hline & Streptococcus pyogenes & $1(\% 0.05)$ \\
\hline & Leuconostoc spp. & $1(\% 0.05)$ \\
\hline \multirow{11}{*}{ Enterebacterales } & K. pneumoniae & $180(\% 10.1)$ \\
\hline & E. coli & $52(\% 2.9)$ \\
\hline & S. marcescens & $33(\% 1.8)$ \\
\hline & K. oxytoca & $27(\% 1.5)$ \\
\hline & Enterobacter spp. & $31(\% 1.7)$ \\
\hline & Proteus spp & $2(\% 0.1)$ \\
\hline & Campylobacter spp. & $1(\% 0.05)$ \\
\hline & Pantoea agglomerans & $1(\% 0.05)$ \\
\hline & Salmonella enteridis & $1(\% 0.05)$ \\
\hline & Salmonella spp. & $1(\% 0.05)$ \\
\hline & Serratia spp. & $1(\% 0.05)$ \\
\hline \multirow{13}{*}{$\begin{array}{l}\text { Non-fermenter bakteriler } \\
\qquad n=169(\% 9,5)\end{array}$} & A. baumannii & $56(\% 3.1)$ \\
\hline & P. aeruginosa & $54(\% 3.02)$ \\
\hline & S. maltophilia & $27(\% 1.5)$ \\
\hline & Acinetobacter /woffii & $11(\% 0.6)$ \\
\hline & Burkholderia cepacia & $8(\% 0.4)$ \\
\hline & Acinetobacter spp. & $4(\% 0.2)$ \\
\hline & Pseudomonas spp. & $3(\% 0.16)$ \\
\hline & Aeromonas salmonicida & $1(\% 0.05)$ \\
\hline & Alcaligenes faecalis & $1(\% 0.05)$ \\
\hline & Brevundimonas spp. & $1(\% 0.05)$ \\
\hline & Chrysebacterium indologenes & $1(\% 0.05)$ \\
\hline & Ralstonıa pıckettı & $1(\% 0.05)$ \\
\hline & Rhizobium radiobacter & $1(\% 0.05)$ \\
\hline \multicolumn{2}{|c|}{ TOPLAM } & $1785(\% 100)$ \\
\hline
\end{tabular}


Akman N. ve Ark.

Tablo 3. . Gram Pozitif Bakterilerin Antimikrobiyal Direnç Profili (n, \%)

\begin{tabular}{lcccc}
\hline Antibiyotikler & S. aureus (65) & S. epidermidis (647) & E. faecium (83) & E. faecalis (88) \\
\hline Ampisilin sulbactam & $12(\% 18.4)$ & $560(\% 87.1)$ & $\mathrm{TE}$ & $\mathrm{TE}$ \\
Ampisilin & $\mathrm{TE}$ & $\mathrm{TE}$ & $69(\% 83.1)$ & $8(\% 9.1)$ \\
Sefazolin & $16(\% 24.6)$ & $549(\% 85.3)$ & $\mathrm{TE}$ & $\mathrm{TE}$ \\
Siproflaksosin & $\mathrm{TE}$ & $\mathrm{TE}$ & $53(\% 63.8)$ & $8(\% 9.1)$ \\
Eritromisin & $21(\% 32.3)$ & $563(\% 87.5)$ & $\mathrm{TE}$ & TE \\
Streptomisin (yüksek düzey) & $\mathrm{TE}$ & $\mathrm{TE} 23.9)$ \\
Gentamisin & $2(\% 3.1)$ & $486(\% 75.5)$ & $35(\% 42.1)$ & $16(\% 18.1)$ \\
(yüksek düzey) & $19(\% 29.2)$ & $490(\% 76.2)$ & $48(\% 57.8)$ & $\mathrm{TE}$ \\
Klindamisin & $15(\% 19.7)$ & $556(\% 86.4)$ & $\mathrm{TE}$ & $\mathrm{TE}$ \\
Metisilin & 0 & $308(\% 47.9)$ & $\mathrm{TE}$ & $\mathrm{TE}$ \\
Rifampin & 0 & 0 & $12(\% 14.4)$ & 0 \\
Vankomisin- teikoplanin & 0 & 0 & 0 & 0 \\
Linezolid & & &
\end{tabular}

Tablo 4. Gram Negatif Bakterilerin Antimikrobiyal Direnç Profili (n, \%)

\begin{tabular}{|c|c|c|c|c|c|}
\hline Antibiyotikler & E. coli (52) & $\begin{array}{c}\text { K. pneumoniae } \\
(180)\end{array}$ & K. oxytoca (27) & $\begin{array}{c}\text { S. marcescens } \\
\text { (33) }\end{array}$ & $\begin{array}{c}\text { Enterobacter spp } \\
\text { (31) }\end{array}$ \\
\hline Amikasin & 0 & $31(\% 17,2)$ & 0 & $6(\% 18,1)$ & $4(\% 12,9)$ \\
\hline Amoksisilin klavonik asit & $17(\% 32,6)$ & $110(\% 61,1)$ & $5(\% 18,5)$ & 0 & $8(\% 25,8)$ \\
\hline Sefepim & $19(\% 36,5)$ & $104(\% 57,7)$ & $5(\% 18,5)$ & $17(\% 51,5)$ & $4(\% 12,9)$ \\
\hline Seftazidim & $\mathrm{TE}$ & $104(\% 57,7)$ & $5(\% 18,5)$ & $16(\% 48,4)$ & $4(\% 12,9)$ \\
\hline Sefotaxim & $19(\% 36,5)$ & $104(\% 57,7)$ & $5(\% 18,5)$ & $1(\% 3,1)$ & $3(\% 9,7)$ \\
\hline Siprofloksasin & $4(\% 7,6)$ & $73(\% 40,5)$ & $5(\% 18,5)$ & $16(\% 48,4)$ & $3(\% 9,7)$ \\
\hline Ertapenem & $5(\% 9,6)$ & $41(\% 22,7)$ & $3(\% 11,1)$ & $4(\% 12,1)$ & TE \\
\hline Meropenem & $4(\% 7,6)$ & $37(\% 20,5)$ & $6(\% 22,2)$ & $4(\% 12,1)$ & $2(\% 6,4)$ \\
\hline İmipenem & $4(\% 7,6)$ & $20(\% 11,1)$ & $3(\% 11,1)$ & 0 & $2(\% 6,4)$ \\
\hline TZP & $5(\% 9,6)$ & $70(38,8)$ & $3(\% 11,1)$ & $6(\% 18,1)$ & $4(\% 12,9)$ \\
\hline Gentamisin & $\mathrm{TE}$ & $\mathrm{TE}$ & $2(\% 7,4)$ & $16(\% 48,4)$ & $2(\% 6,4)$ \\
\hline Levofloksasin & $\mathrm{TE}$ & $\mathrm{TE}$ & 0 & $8(\% 24,2)$ & 0 \\
\hline TMP/SMX & $\mathrm{TE}$ & $\mathrm{TE}$ & 0 & $7(\% 21,2)$ & $1(\% 3,2)$ \\
\hline Kolistin & $1(\% 1,9)$ & $12(\% 6,6)$ & $2(\% 7,4)$ & $1(\% 3,1)$ & 0 \\
\hline Tigesiklin & $\mathrm{TE}$ & $1(0,5)$ & 0 & $4(\% 12,1)$ & 0 \\
\hline ÇiD & $11(\% 22,4)$ & $82(\% 45,5)$ & $4(\% 14,8)$ & $18(\% 54,5)$ & $6(\% 19,4)$ \\
\hline
\end{tabular}

TZP: piperacillin-tazobactam; TMP/SMX: Trimetoprim-Sulfametoksazol; TE: test edilmedi; çiD: çoklu ilaç direnci 
Akman N. ve Ark.

Tablo 5. . Non-fermentatif Bakterilerin Antimikrobiyal Profili (n, \%)

P. aureginosa (54)

A. baumannii (56)

\begin{tabular}{lcc}
\hline Amikasin & $8(\% 14.8)$ & $40(\% 71.4)$ \\
Sefepim & $10(\% 18.5)$ & $8(\% 14.2)$ \\
Sefaperozone-sulbactam & $10(\% 18.5)$ & TE \\
Seftazidim & $12(\% 22.2)$ & $11(\% 19.6)$ \\
Kolistin & $1(\% 1.8)$ & $13(\% 23.2)$ \\
İmipenem & $36(\% 66.6)$ & $39(\% 69.6)$ \\
Meropenem & $34(\% 62.9)$ & $44(\% 78.5)$ \\
TZP & $17(\% 31.4)$ & 0 \\
Siproflosasin & $13(\% 24.1)$ & $47(\% 83.9)$ \\
Gentamisin & $13(\% 24.1)$ & $56(\% 82.1)$ \\
Tobramisin & $3(\% 5.5)$ & TE \\
Levofloksasin & TE & $32(\% 57.1)$ \\
TMP/SMX & TE & $47(\% 83.9)$ \\
ÇiD & $13(\% 24.1)$ & $49(\% 87.5)$ \\
\hline
\end{tabular}

TZP: piperacillin-tazobactam; TMP/SMX: Trimetoprim-Sulfametoksazol; TE: test edilmedi çiD: çoklu ilaç direnci 